\title{
Hereditary Colorectal Cancer in China: Current Status and Progress
}

\author{
Chen-Guang $\mathrm{Li}^{\mathrm{a}, \mathrm{b}} \quad$ Lang Yang $^{\mathrm{a}} \quad$ Jian-Qiu Sheng ${ }^{\mathrm{a}}$ \\ ${ }^{a}$ Department of Gastroenterology, General Hospital of Beijing Military Region, Beijing, and \\ ${ }^{\mathrm{b}}$ The Third Military Medical University, Chongqing, China
}

\section{Key Words}

Clinicopathological features - Diagnostic criteria - Genetics · Hereditary colorectal cancer . Intervention

\begin{abstract}
Background: Hereditary colorectal cancer (CRC) accounts for about $5 \%$ of the total incidence of CRC. During the last decades, there have been great advances in the research of hereditary CRC in China. Summary: This review mainly focuses on advances of the genetic basis, clinicopathological features, diagnosis, chemoprevention and treatment of hereditary CRC in China. Key Message: Hereditary CRC has a higher risk to initiate the progression towards neoplasia than sporadic CRC. It can be diagnosed by clinical manifestation or the relevant genetic testing so as to guide the clinical treatment to improve the survival rate and survival quality of patients. Practical Implications: Hereditary CRC includes hereditary nonpolyposis CRC (Lynch syndrome), familial adenomatous polyposis and other rare types such as PeutzJeghers syndrome and familial juvenile polyposis. Based on the clinical manifestations and family history, highly suspected cases can be screened for in the general population and the diagnosis ruled out by genetic analysis. Then, chemoprevention, endoscopic intervention or surgery can be selected properly to improve patients' survival and quality of life.
\end{abstract}

(C) 2015 S. Karger AG, Basel

\section{Introduction}

The incidence of colorectal cancer (CRC) in the general population was 20.90/1,000,000 in 2012 in China [1]. The number of new cases of CRC is growing year by year. Hereditary CRC accounts for nearly $5 \%$ of all CRC cases [2,3]. Hereditary CRC was classified as hereditary

All three authors contributed equally to this work. 
nonpolyposis CRC (HNPCC) and hereditary colorectal polyposis [4]. In addition, hereditary colon polyposis disease can be subdivided into adenomatous polyposis syndrome including familial adenomatous polyposis (FAP), MutY homologue-associated polyposis (MAP) and hamartoma polyposis syndrome, such as Peutz-Jeghers syndrome (PJS), familial juvenile polyposis coli (FJPC), phosphatase and tensin homolog (PTEN) hamartoma tumor syndrome (PHTS) and hereditary mixed polyposis syndrome (HMPS) [5]. The aim of this review was to summarize the current knowledge of hereditary CRC in China by searching relevant studies published between 2005 and 2015 on PubMed, China Academic Journal Network Publishing Database (CAJD) and Vip Journal Integration Platform.

\section{Hereditary Nonpolyposis Colorectal Cancer}

HNPCC, also known as Lynch syndrome, is an autosomal dominant genetic condition which has a high risk of colon cancer as well as extracolonic cancers due to inherited mutations in mismatch repair (MMR) genes. HNPCC is the most common form of hereditary CRC, accounting for $0.5-1.2,2.1-2.9$ and $2.4-2.9 \%$ of all CRC cases, respectively, according to the Amsterdam Criteria I and II and to the Japanese Criteria in China [6, 7]. The 3-, 5- and 10-year survival rates are 70.3, 49.9 and $39.7 \%$ in China, respectively. The incidence of multiple primary neoplasms in HNPCC was $20.4 \%$ [8].

\section{Genetics}

It had been confirmed that the germline mutations in MMR genes are the genetic basis of HNPCC [9]; mutations in MMR genes MLH1, MSH2, MSH6, PMS2 and EPCAM are associated with HNPCC. Besides, mutations in MSH3, PMS1 and MLH3 have been reported to be the pathogenesis of HNPCC in China [9-15]. Among the MMR gene mutations, hMLH1 accounts for about $49-57 \%$, while hMSH2 accounts for about $45-49 \%$, and the deletion of hMLH1 seems to be more important than MSH2 in early-onset CRC [16-19]. However, some scholars found that among CRC patients in Beijing, HNPCC has a higher morbidity (13.83\%) than the average level in the world (2-5\% [20]), and MSH2 mutation is very frequent (84.62\%) [21]. Besides, Long et al. [22] examined MMR protein expression by using immunohistochemistry (IHC) in 173 patients with endometrial cancer and found that the loss rates of MSH6, MSH2, PMS2 and MLH1 protein was 16.18\% (28/173), 12.14\% (21/173), 7.51\% (13/173) and $5.78 \%$ (10/173), respectively. Liu et al. [23] screened a total of 116 unrelated probands of suspected HNPCC families from the Fudan Colorectal Registry and have found that patients with hMSH2 mutation were frequently affected by synchronous and metachronous colon cancers. Certainly, more studies are needed to clarify the mutation rates of MLH1 and MSH2 in China.

\section{Clinical Features}

Here we list some well-recognized HNPCC clinicopathological manifestations: (1) early onset age - the median age is about 45 years and the onset age of offspring is decreasing compared to their parents' generation; (2) appropriately $70 \%$ of tumors are located in the right-sided colon [24]; (3) there is a high risk of synchronous or metachronous primary CRCs, and $40 \%$ of HNPCC patients will develop a new CRC within 10 years after partial colon resection; (4) extracolonic cancer can co-exist, including endometrial cancer, ovarian cancer, gastric cancer, small intestine cancer, hepatobiliary cancer and urinary cancer; (5) poor differentiated adenocarcinoma, mucous carcinoma or signet ring cell carcinoma are more frequent and accompanied with lymphocyte infiltration. 


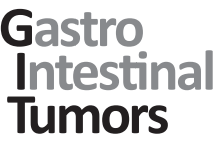

Table 1. Amsterdam criteria I and II [91]

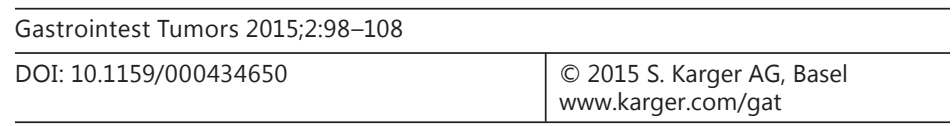

\author{
Amsterdam criteria I \\ At least three relatives with CRC; all of the following must be met: \\ 1 One patient must be a first-degree relative of the other two \\ 2 At least two successive generations affected \\ 3 At least one CRC diagnosed before age 50 \\ $4 \quad$ FAP has been excluded
}

\section{Amsterdam criteria II}

At least three relatives with colorectal, endometrial, small bowel, ureter, or renal pelvis cancer; all of the following must be met:

1 One patient must be a first-degree relative of the other two

2 At least two successive generations affected

3 At least one CRC diagnosed before age 50

4 FAP has been excluded

HNPCC patients have better prognosis than those with sporadic CRC [25]. Chinese HNPCC patients have some different features [26, 27]. The most frequent extracolonic cancer in China is gastric cancer, not endometrial cancer as reported in western studies [27, 28]. The median age at the onset of HNPCC is 45.3 years in Jiangxi province and 41.8 years in the city of Wuhan, which is similar to western countries $[29,30]$. Jin et al. $[8,31]$ reported that the 3-, 5- and 10-year survival rates of HNPCC in China were 61.7, 38.11 and 25.81\% in 2001 and increased to $70.3,49.9$ and $39.7 \%$ in 2005 , respectively, suggesting that the prognosis of HNPCC had improved within 5 years, which was probably associated with early detection and timely treatment.

\section{Diagnostic Criteria and Methods}

The diagnosis of HNPCC mainly relies on family history and genetic linkage analysis. Patients meeting the Amsterdam criteria or Bethesda guidelines should undergo detection of microsatellite instability (MSI) and IHC analysis of hMSH2 and hMLH1 expression [32]. At present, there are some international standards on HNPCC, such as the Amsterdam criteria I and II (table 1), the Bethesda guidelines and Japanese standards. The Amsterdam criteria are widely used to screen for HNPCC. However, they are not suitable for small pedigrees, which are common in China, and some Chinese scholars think that the characteristics of HNPCC in the Chinese population are probably different from those of western countries. So the Chinese Association of Professional Committee of Colorectal Cancer has established the Chinese criteria [33]: there must be at least two relatives with CRC, two of them first-degree relatives; all of the following must be met: (1) at least one patient with multiple CRC or adenomas; (2) at least one CRC diagnosed before the age of 50 years; (3) at least one patient with extracolonic tumors, such as gastric carcinoma, endometrial cancer, small bowel cancer, ureteral or renal pelvis carcinoma, ovarian cancer, hepatobiliary system cancer, etc.

Genetic Testing. When the above-mentioned criteria are met, the MSI and MMR genes should be examined to identify families with HNPCC. Many Chinese scholars detected microsatellite loci in HNPCC patients, including BAT25, BAT26, D2S123, D5S346 and D17S250, and found that MSI-H positivity was about $85.0 \%$, the MSI rates of BAT25 and BAT26 being close to $100 \%$. We also found that in northern Chinese patients with HNPCC, MSI-H positivity was $83.3 \%$, and expression loss of MMR proteins accounted for about $88 \%$ of MSI-H patients, the pathogenic mutation rate of the MMR gene being 56\% [34]. Because of the high incidence of MSI-H in HNPCC, MSI detection is a simple and easy way to screen for early germline mutations in MMR genes [35, 36]. Besides, IHC is a good substitutive way to evaluate the mutation of hMLH1 and hMSH2 [22]. Jin et al. [37] found that the specificity and sensitivity of IHC for 
hMLH1 and hMSH2 were 91.7 and $87.5 \%$, respectively. If both MSI and IHC results are negative, the mutation detection analysis is unnecessary. If one of them is positive, hMLH1 and hMSH2 germline mutations should be detected [34]. At present, most Chinese scholars have found that it is very effective to test the MLH1 and MSH2 gene to screen HNPCC patients [38-44]. Zhou et al. [45] reported that promoter methylation analysis in MLH1 was a promising tool for HNPCC screening.

\section{Treatment}

Chemoprevention. Nonsteroidal anti-inflammatory drugs have been proved to be a class of effective drugs in the intervention for FAP and HNPCC. We found that oral administration of celecoxib was effective. The patients treated by celecoxib $400 \mathrm{mg}$ daily combined with endoscopic intervention showed protective effectiveness [46]. A report said that aspirin does not have a protective effect against CRC in the short term, but that long-term aspirin treatment has a protective effect against Lynch syndrome cancers [47].

Operative Treatment. Surgery is still the main way for the treatment of HNPCC, but there are some controversies about the optimal operative methods. Some scholars have proposed that total colectomy should be implemented to avoid the risk of multiple primary CRC and the misdiagnosis of residual colon once the diagnosis is confirmed [48]. However, some scholars have considered that extracolonic organs may suffer HNPCC-related tumors after total colectomy [49]. Presently, the National Comprehensive Cancer Network guidelines advise HNPCC patients with incipient CRC to choose total colectomy. Besides, clinical stage, prognosis, follow-up conditions and personal wishes should all be considered before choosing preventive surgery. Whether the rectum was retained or not is critical to postoperative quality of life. What is more, most HNPCC tumors are located in the proximal colon. If there is no lesion in the proximal colon, the proximal colon should be retained and the patient needs to be examined at regular intervals. When a lesion is detected, surgical treatment is recommended. In addition, endoscopic intervention has been proved to be an effective alternative way of managing HNPCC patients. We found that in MMR mutation carriers, colonoscopic surveillance can facilitate the diagnosis of more early-stage CRC than non-surveillance [50]. Moreover, Li et al. [51] reported that colonoscopic surveillance is an important way to decrease the incidence of CRC and to lower the overall mortality of HNPCC family members with MMR genes mutations.

\section{Familial Adenomatous Polyposis}

FAP is an autosomal-dominant CRC syndrome, caused by a germline mutation in the adenomatous polyposis coli (APC) gene located on chromosome 5q21 [52]. FAP is a representative form of the adenomatous polyp syndrome, and the incidence rate is about 1/7,00022,000 . It can be divided into classical FAP, attenuated FAP, MAP, Gardner syndrome and Turcotsyndrome [49]. Liu etal. [53] reported that the morbidity of FAP was about 1.5/100,000 in Zhejiang province of China.

\section{Genetics}

The present study suggests that FAP is mainly caused by APC and MYH mutation; $25 \%$ of FAP cases without APC mutation are caused by MYH mutation [54]. There are one mutational allele and one normal allele of the APC gene in FAP patients. It is a classical Mendelian genetic disease. 79\% of FAP patients have one mutated allele [55]. The APC gene is a housekeeping gene, and its length of open reading frame is $8,535 \mathrm{bp}$, containing 15 exons. The 15 th exon is the longest one $(6,577 \mathrm{bp})$, accounting for about $77 \%$ of the full-length gene (exon). The 
Table 2. Clinical features of FAP

\begin{tabular}{llll}
\hline Type & $\begin{array}{l}\text { Average } \\
\text { onset age }\end{array}$ & $\begin{array}{l}\text { Number } \\
\text { of polyps }\end{array}$ & Parenteral complications \\
\hline $\begin{array}{l}\text { Classical } \\
\text { FAP }\end{array}$ & 39 [92] & $>100$ & $\begin{array}{l}\text { congenital hypertrophy of the retinal pigment epithelium } \\
\text { thyroid papillary carcinoma } \\
\text { adrenal hyperplasia or carcinoma } \\
\text { fundic gland polyps } \\
\text { periampullary adenoma of the duodenum } \\
\text { Gardner and Turcot syndrome [73] }\end{array}$ \\
\hline $\begin{array}{lll}\text { Attenuated } \\
\text { FAP }\end{array}$ & $55[92]$ & $<100$ & $\begin{array}{l}\text { fundic gland polyps } \\
\text { duodenal periampullary adenoma }\end{array}$ \\
\hline MAP & $55[93]$ & dozens or & $\begin{array}{l}\text { not clear, but there were some reports about fundic gland } \\
\text { polyps and duodenal periampullary adenoma [72] }\end{array}$ \\
\hline
\end{tabular}

product of the APC gene is a protein with 2,843 amino acids, and the molecular weight is about $310 \mathrm{kDa}$. APC gene mutations mainly include missing, insertion mutations, point mutations or frame shift mutations [56]. Besides the hot spot 1,250-1,464 bp, some Chinese scholars have reported that APC gene mutations can occur within the area 443-1,068 bp and the splicing area in intensive polyp patients. The average onset age in China is 32 years, while in western countries the onset age of intensive FAP is 10-20 years and that of middle type 20-30 years [57-59]. Another FAP-associated gene is MYH. The MYH gene is located at p34.3p32.1 and contains 16 exons; its coding protein is a transglucosylase which participates in repairing and splicing of the bases. MYH is an autosomal recessive gene found in colorectal multiple polyp or typical adenomatous polyp patients [60,61]. MYH gene mutation can lead to high risk of colorectal polyps and adenocarcinoma. Recently, Yang et al. [62] reported that there was a relationship between AXIN2 gene mutation and FAP.

\section{Clinical Features}

In the surgery clinic, hematochezia is the main clinical symptom of FAP, accompanied by anemia, abdominal pain, diarrhea, mucus stool, etc. Additionally, a few patients can have symptoms of intussusception or intestinal obstruction [63]. However, in the internal medicine clinic, diarrhea is the most frequent symptom of FAP, accounting for $71.0 \%$, followed by abdominal pain (29.0\%) and hematochezia (16.1\%) [64]. What is more, Li et al. [65] also reported that diarrhea was the most frequent manifestation. The discrepancy in clinical manifestation may be caused by the difference in patients choosing between surgical and internal medicine departments.

The most typical characteristic of FAP patients is $>100$ tubular or villous adenomas in the whole colon [66]. An intensive polyp number over 1,000 is a common phenotype of FAP in China [55]. FAP patients often suffer from stomach, duodenum and ileum polyps, with an occurrence of 30-90\% [67]. Duodenal carcinoma is considered to be the second most important cause of death $[68,69]$. The characteristics of classical FAP, attenuated FAP and MAP are listed in table 2.

\section{Diagnostic Criteria and Methods}

The diagnostic criteria for FAP are (1) >100 colorectal adenomas, with or without a family history, and (2) >20 colorectal adenomas with a family history. An APC gene mutation test is recommended once the patients meet the above criteria [34]. A recent study suggests that MYH and AXIN2 should be detected if APC gene mutation is negative [62]. 


\section{Clinical Screening}

There are some major checking methods, such as endoscopic examination and genetic testing. In order to find the parenteral tumors, it is important to examine the fundus [70], the thyroid gland, the reproductive system and any other systems when the patients have been diagnosed [71].

Treatment

Chemoprevention. The nonselective and selective inhibitors of COX- 2 are the major drugs for the treatment of FAP, including sulindac and celecoxib. A lot of reports say that nonsteroidal anti-inflammatory drugs can reduce the number and size of FAP adenomas [62, 65-76]. Sulindac in combination with endoscopic treatment is better than polyp resection to suppress colorectal adenoma development in the long term. Quality of life is better than with mere surgical treatment and patient compliance is lower $[77,78]$. Besides, berberine inhibits colon tumor formation through inhibition of Wnt/beta-catenin signaling, indicating that berberine may be a promising drug for the prevention of colon cancer [79]. In traditional medicine, Wang et al. [80] have reported that black raspberries suppositories are effective to restrain the development of polyps in patients with FAP.

Operative Treatment. Ileal pouch anal anastomosis is the first surgical choice for FAP. However, many patients still die from Gardner or Turcot syndrome. Thus, it is important to adopt individualized treatment, depending on the patients' age, the number and distribution of colorectal polyps and intercurrent upper gastrointestinal polyp, Gardner and Turcot syndrome, and the desire of the patients and their families [81]. Surgical treatment can be applied to patients older than 15-18 years [82]. In order to improve quality of life, patients can choose subtotal colectomy to retain the rectum. Patients then need to undergo colorectal endoscopic examination every 6 months. For relapsed adenomas, it is necessary to adopt electroresection combined with nonsteroidal drugs.

\section{Hamartomatous Polyposis Syndrome}

Hamartomatous polyposis syndrome is a rare genetic polyposis including PJS, FJPC, PHTS and HMPS.

Peutz-Jeghers Syndrome

The mainly representative hamartomatous polyposis syndrome is PJS. The incidence of PJS is about $1 / 25,000$. Skin and mucosa pigment spots, gastrointestinal hamartomatous polyps and familial transmissibility are major clinical features [83, 84].

Familial Juvenile Polyposis Coli

FJPC is characterized by multiple colorectal juvenile polyps, and the incidence is about $1 / 1,000,000$. 'Juvenile' refers to the histology of polyps rather than the onset age $[85,86]$. The clinical characteristics of PJS and FJPC are listed in table 3.

\section{Treatment}

The main clinical treatment on PJS and FJPC is surgery combined with endoscopic therapy. Small and pedicle polyps should be eliminated as soon as possible. Surgical treatment should be considered if the patient is suffering from refractory bleeding, severe anemia and malnutrition, or if the polyps cannot be removed by endoscopic excision [87]. 
Table 3. Clinical characteristics of PJS and FJPC

\begin{tabular}{|c|c|c|c|c|}
\hline Condition & $\begin{array}{l}\text { Mutation gene } \\
\text { test }\end{array}$ & & Clinical characteristics & Diagnosis \\
\hline \multirow[t]{3}{*}{ PJS } & \multirow[t]{3}{*}{$\begin{array}{l}\text { LKB1/STK11 } \\
\text { FHIT }[34,94]\end{array}$} & 1 & $\begin{array}{l}\text { polyps of various sizes distributed in } \\
\text { the digestive tract, frequently in the } \\
\text { jejunum }\end{array}$ & \multirow[t]{3}{*}{$\begin{array}{l}\text { multiple hamartoma } \\
\text { polyps with mucocutaneous } \\
\text { pigmentation }\end{array}$} \\
\hline & & 2 & $\begin{array}{l}\text { acute or chronic abdominal pain, } \\
\text { intussusception, volvulus, } \\
\text { intestinal obstruction [87] and } \\
\text { gastrointestinal bleeding }\end{array}$ & \\
\hline & & 3 & $\begin{array}{l}\text { parenteral tumors, such as breast } \\
\text { cancer and reproductive system } \\
\text { tumor [83] }\end{array}$ & \\
\hline \multirow[t]{3}{*}{ FJPC } & \multirow[t]{3}{*}{$\begin{array}{l}\text { BMPR1A/SMAD4 } \\
{[95,96]}\end{array}$} & 1 & $\begin{array}{l}\text { infantile type: it is relatively rare; } \\
\text { the baby manifests with mucus } \\
\text { diarrhea, vomiting, hematochezia } \\
\text { within a few weeks after birth }\end{array}$ & $\begin{array}{l}1 \text { Jass diagnostic criteria [97]: } \\
>5 \text { colorectal juvenile polyps }\end{array}$ \\
\hline & & 2 & $\begin{array}{l}\text { colorectal type: } 50-200 \text { polyps, } \\
\text { located in the sigmoid colon and } \\
\text { rectum; the main symptoms are } \\
\text { hematochezia and mucous stool }\end{array}$ & \multirow[t]{2}{*}{$\begin{array}{l}\text { the whole gastrointestinal } \\
\text { tract is affected, with a family } \\
\text { history }\end{array}$} \\
\hline & & 3 & $\begin{array}{l}\text { diffuse type: the polyps can be } \\
\text { detected in the whole gastro- } \\
\text { intestinal tract and upper gastro- } \\
\text { intestinal hemorrhage is common } \\
\text { [95-98] }\end{array}$ & \\
\hline
\end{tabular}

\section{Challenges and Perspectives}

Although there have been great advances in the research of hereditary CRC in China, there is yet no multicenter organization to study hereditary CRC, nor has there been nationwide research on epidemiological investigation. Many valuable cases of hereditary CRC are not effectively managed, which is a key problem for the research of hereditary CRC in China. In the future, there are some issues that should be considered to reveal the basic and clinical aspects of hereditary CRC. First, high-throughput sequencing, the so-called next-generation sequencing technology, makes it possible to analyze the whole genome. This revolutionary technology will be able to provide a new way to analyze the pathogenic genes of hereditary CRC. Maybe some new variants responsible for hereditary CRC can be found out by nextgeneration sequencing. Second, mutation in the gene intron has been reported in heredity CRC [88], but whether it is pathogenic or not still needs to be ascertained. Third, a report from the USA demonstrated that microRNAs play an important role in the development of HNPCC and FAP [89]. MicroRNAs can specifically target MMR mRNAs involved in colon cancer progression [90], suggesting that epigenetic dysfunction may involve in the pathogenesis of heredity CRC. However, how those factors influence the initiation and progression of hereditary CRC remains unclear. Finally, it is estimated that there are only small subpopulations of candidates joined in the program of hereditary CRC screening, thus some of the patients suffering fro hereditary CRC may be missed. This may be related to the lesser number of centers and to doctors' proficiency. 


\section{Acknowledgments}

This work was funded by National Natural Science Foundation of China (NSFC No. 81272194).

\section{Disclosure Statement}

The authors declare that they have no conflict of interest.

\section{References}

1 International Agency for Research on Cancer: GLOBOCAN 2012: estimated cancer incidence, mortality and prevalence worldwide in 2012. http://globocan.iarc.fr/Pages/fact_sheets_cancer.aspx.

$\longrightarrow 2$ Kim JC, Kim SY, Roh SA, et al: Gene expression profiling: canonical molecular changes and clinicopathological features in sporadic colorectal cancers. World J Gastroenterol 2008;14:6662-6672.

3 Chen MQ, Zhu Z, Dai LP, et al: Establishment and management of hereditary colorectal cancer tissue bank in Yunnan province. Shijie Huaren Xiaohua Za Zhi 2008;16:3122-3125.

4 Yuan Y: Yi chuan xing da chang ai de yan jiu jin zhan. Yi Xue Xin Zhi Za Zhi 2008;6:311-314, 374.

5 Ding Z: Yi chuan xing jiezhi chang ai de ti xi jie gou he zhen zhi jin zhan. Zhonghua Jiezhichang Jibing Dianzi Za Zhi 2013;2:184-190.

-6 Zhang YZ, Sheng JQ, Li SR, et al: Hereditary predisposition of colorectal cancer and prevalence of hereditary nonpolyposis colorectal cancer in general population of colorectal cancer patients in China (in Chinese). Zhonghua Yi Xue Za Zhi 2005;85:2995-3000.

7 Zhang YZ, Wu ZT, Li SR: Clinical pathology and hereditary predisposition in patients with primary colorectal cancer: an analysis of 594 cases. Shijie Huaren Xiaohua Za Zhi 2004;12:1809-1813.

$>8$ Jin HY, Cui L, Ding YJ, et al: Analysis of the clinicopathological features of Chinese hereditary nonpolyposis colorectal cancer (in Chinese). Zhonghua Wei Chang Wai Ke Za Zhi 2005;8:316-318.

$\checkmark 9$ Castells A, Balaguer F, Castellví-Bel S, et al: Identification of Lynch syndrome: how should we proceed in the 21st century? World J Gastroenterol 2007;13:4413-4416.

10 Gu GL, Zhou XW, Wang SL: Clinical prospects and research progress in hereditary non-polyposis colorectal cancer. Shijie Huaren Xiaohua Za Zhi 2007;15:3115-3121.

11 Giardiello FM, Brensinger JD, Petersen GM: AGA technical review on hereditary colorectal cancer and genetic testing. Gastroenterology 2001;121:198-213.

12 Lynch HT, de la Chapelle A: Genetic susceptibility to non-polyposis colorectal cancer. J Med Genet 1999;36: 801-818.

13 Zhang SY, Yu ZJ: Hereditary nonpolyposis colorectal cancer genetic susceptibility genes research status. Wei Chang Bing Xue He Gan Bing Xue Za Zhi 2012;21:989-993.

14 Pérez-Cabornero L, Infante Sanz M, Velasco Sampedro E, et al: Frequency of rearrangements in Lynch syndrome cases associated with MSH2: characterization of a new deletion involving both EPCAM and the $5^{\prime}$ part of MSH2. Cancer Prev Res (Phila) 2011;4:1556-1562.

15 Zhang H: The clinical characterization of HNPCC families from northern Chinese population and the role of hMLH3 and hEXO1 germline mutation in HNPCC. Doctoral dissertation, Third Military Medical University, Chongqing, 2005.

16 Wang Y, Tong J: Expression of hMLH1 and hMSH2 in suspected hereditary non-polyposis colorectal cancer. Shi Yong Yi Xue Za Zhi 2014,30:2061-2064.

17 Yang L, Ding YQ, Li GX, et al: Microsatellite analysis and hMLH1/hMSH2 expression detection in young patients with colorectal cancer: value in screening hereditary nonpolyposis colorectal cancer (in Chinese). Nan Fang Yi Ke Da Xue Xue Bao 2007;27:779-782.

18 Wei W, Liu F, Liu L, et al: Distinct mutations in MLH1 and MSH2 genes in hereditary non-polyposis colorectal cancer (HNPCC) families from China. BMB Rep 2011;44:317-322.

19 Meng J, Li XX, Zhao M, et al: Relationship between the expressions of hMLH1 and hMSH2 protein and clinicopathological features and prognosis of hereditary nonpolyposis colorectal cancer. Zhong Guo Pu Wai Ji Chu Yu Lin Chuang Za Zhi 2013;1:66-70.

20 Lynch HT, Boland CR, Gong G, et al: Phenotypic and genotypic heterogeneity in the Lynch syndrome: diagnostic, surveillance and management implications. Eur J Hum Genet 2006;14:390-402.

21 Nie C, Li Y, Zhao B, et al: Molecular pathological character of hereditary nonpolyposis colorectal cancer. Zhong Guo Yi Yao Dao Bao 2014;30:23-25, 33.

22 Long Q, Peng Y, Tang Z, et al: Role of endometrial cancer abnormal MMR protein in screening Lynch-syndrome families. Int J Clin Exp Pathol 2014;7:7297-7303.

23 Liu F, Yang L, Zhou X, et al: Clinicopathological and genetic features of Chinese hereditary nonpolyposis colorectal cancer (HNPCC). Med Oncol 2014;31:223. 
24 Zhao Y, Oki E, Ando K, et al: The impact of a high frequency microsatellite instability phenotype on the tumor location related genetic differences in colorectal cancer. Cancer Genet Cytogenet 2010;196:133-139.

25 Jasperson KW, Tuohy TM, Neklason DW, et al: Hereditary and familial colon cancer. Gastroenterology 2010; 138:2044-2058.

26 Yan YF, Li XX, Tang YX, et al: Clinicopathologic features analysis of patients with hereditary nonpolyposis colorectal cancer in northeast Chinese. Zhong Guo Pu Wai Ji Chu Yu Lin Chuang Za Zhi 2013;2:138-142.

27 Zhang H, Wang J, Sheng JQ, et al: The clinical characterization of hereditary nonpolyposis colorectal cancer families from Chinese population. Wei Chang Bing Xue He Gan Bing Xue Za Zhi 2005;14:186-189.

28 Chen C, Chen JG, Wang Q: Clinical features of hereditary non-polyposis colorectal cancer in Wuhan: an analysis of 8 pedigrees. Lin Chuang Wu Zhen Wu Zhi 2007;20:14-16.

29 Li TY, Liu DN, Jiang QG: 15 ge yi chuan xing fei xi rou xingdachangai jiaxi de lin chuang fen xi. Shi Yong Lin Chuang Yi Xue (Jiang Xi) 2009;10:60.

30 Li JS, Yu MP, Mo SJ: Analysis on 64 cases of hereditary nonpolyposis colorectal carcinoma in 18 family lines. Zhong Guo Zhong Xi Yi Jie He Wai Ke Za Zhi 2010;16:619-623.

31 Jin HY, Chui L, Meng R, et al: The clinicopathological features of 19 nontypical pedigrees of hereditary nonpolyposis colorectal cancer. Wai Ke Li Lun Yu Shi Jian 2001;6:393-394.

32 Jass JR: Hereditary non-polyposis colorectal cancer: the rise and fall of a confusing term. World J Gastroenterol 2006;12:4943-4945.

33 Yuan Y, Zhang SZ, Zheng S, et al: Zhong guo ren yi chuan xing da chang ai shai jian biao zhun de shi shi fang an. Zhong Hua Zhong Liu Za Zhi 2004;26:191-192.

34 Sheng J, Chen X, Sun Z, et al: Microsatellite instability and novel mismatch repair gene mutations in northern Chinese population with hereditary nonpolyposis colorectal cancer. Wei Chang Bing Xue He Gan Bing Xue Za Zhi 2008;4:287-290.

35 Liu WZ, Yin JJ, Wang YD, et al: Research of detection role of microsatellite instability in northern China people with HNPCC. Chin J Cancer Prev Treat 2007;14:1527-1530.

36 Sheng JQ, Tian SL, Lv Y, et al: Study of microsatellite instability in hereditary nonpolyposis colorectal cancer. Wei Chang Bing Xue He Gan Bing Xue Za Zhi 2004;5:537-539.

37 Jin HY, Cui L, Meng RG, et al: The role of the immunohistochemistry for hMLH1 and hMSH2 with detection of microsatellite instability to identify the kindreds with hereditary nonpolyposis colorectal cancer. Zhonghua Wai Ke Za Zhi 2003;41:809-811.

38 Peng Y, Tan XY: Detection of endometrial cancer MMR protein in screening HNPCC families. Lin Chuang Yu Shi Yan Bing Li Xue Za Zhi 2013;29:1317-1319.

39 Liu WZ, Wang YD: Detection of hMLH1/hMSH2 expression for identifying patients with hereditary nonpolyposis colorectal carcinoma. Zhong Guo Ai Zheng Za Zhi 2009;19:662-666.

40 Zhang YZ, Sheng JQ, Zhang H, et al: Cumulative cancer risk of hMLH1 and hMSH2 germline mutation carriers in HNPCC families. Xian Dai Sheng Wu Yi Xue Jin Zhan 2009;9:2854-2857.

41 Hou RZ, An ZG, Wei J, et al: Screening of susceptible gene hMLH1 and hMSH2 in colorectal cancer. Zhong Guo Shi Yan Zhen Duan Xue 2012;1:49-51.

42 Fang FD: Ren cuo pei xiu fu ji yin hMLH1 yan jiu de xin jin zhan. Ji Chu Yi Xue Yu Lin Chuang 2012;4:337.

43 Chen H: Expression of hMLH1 hMSH2 and its correlation in gallbladder cancer. Tai Shan Yi Xue Yuan Xue Bao 2012;1:19-22.

44 Ning LS, Ding YS, Miao T, et al: Clinical significance of the expression of hMLH1 and hMSH2 in colorectal cancer. Zhong Guo Xian Dai Pu Tong Wai Ke Jin Zhan 2012;5:370-373.

45 Zhou HH, Yan SY, Zhou XY, et al: MLH1 promoter germline-methylation in selected probands of Chinese hereditary non-polyposis colorectal cancer families. World J Gastroenterol 2008;14:7329-7334.

-46 Sheng JQ, Li SR, Yang XY, et al: Clinical management of adenomatous polyposis in patients with hereditary non-polyposis colorectal cancer and familial adenomatous polyposis. Zhong Hua Yi Xue Za Zhi 2006;8:526529.

47 Mathers JC, Movahedi M, Macrae F, et al: Long-term effect of resistant starch on cancer risk in carriers of hereditary colorectal cancer: an analysis from the CAPP2 randomised controlled trial. Lancet Oncol 2012;13: 1242-1249.

48 Koomstra JJ, Mourits MJ, Sijmons RH, et al: Management of extracolonic tumours in patients with Lynch syndrome. Lancet Oncol 2009;10:400-408.

49 Kanter-Smoler G, Fritzell K, Rohlin A, et al: Clinical characterization and the mutation spectrum in Swedish adenomatous polyposis families. BMC Med 2008;6:10.

$50 \mathrm{Fu}$ L, Sheng JQ, Li XO, et al: Mismatch repair gene mutation analysis and colonoscopy surveillance in Chinese Lynch syndrome families. Cell Oncol (Dordr) 2013;36:225-231.

51 Li XO, Li CL, Zhang HW, et al: The clinical significances of concomitant colonoscopies in hereditary nonpolyposis colorectal cancer family members with MMR gene mutation. Shi Yong Yi Xue Za Zhi 2013;29:2279_ 2280 .

52 Galiatsatos P, Foulkes WD: Familial adenomatous polyposis. Am J Gastroenterol 2006;101:385-398.

53 Liu J, Zheng S, Feng YZ, et al: Preliminary report on registration and family survey of familial adenomatous polyposis. Chin J Clin Oncol 1997;24:756-759.

54 Yang SY, Cai SR, Zhang SZ: Jia zu xing xian liu xing xi rou bing ji qi ya xing de lin chuang ji yi chuan biao xing. Shi Yong Zhong Liu Za Zhi 2007;22:270-273. 
55 Cui WJ, Sheng JQ, Lu XJ: Genotype-phenotype correlations in Chinese familial adenomatous polyposis (FAP). Ji Chu Yi Xue Yu Lin Chuang 2009;6:589-592.

56 Howe JR, Guillem JG: The genetics of colorectal cancer. Surg Clin North Am 1997;77:175-195.

57 Ficari F, Cama A, Valanzano R, et al: APC gene mutations and colorectal adenomatosis in familial adenomatous polyposis. Br J Cancer 2000;82:348-353.

58 Nieuwenhuis MH, Vasen HF: Correlations between mutation site in APC and phenotype of familial adenomatous polyposis (FAP): a review of the literature. Crit Rev Oncol Hematol 2007;61:153-161.

59 Miyaki M, Seki M, Okasmoto M, et al: Genetic changes and histopathological types in colorectal tumors from patients with familial adenomatous polyposis. Cancer Res 1990;50:7166-7173.

60 Sieber OM, Lipton L, Crabtree M, et al: Multiple colorectal adenomas, classic adenomatous polyposis, and germline mutation in MYH. N Engl J Med 2003;248:791-799.

61 Cazorla A, Viennet G, Uro-Coste E, et al: Mucoepidermoid carcinoma: a yet unreported cancer associated with familial adenomatous polyposis. J Craniomaxillofac Surg 2014;42:262-264.

-62 Yang J, Liu WQ, Li WL, et al: Detection of APC, MYH and AXIN2 gene mutations for screening germline mutations predisposing to familial adenomatous polyposis. Shijie Huaren Xiaohua Za Zhi 2015;23:556-562.

63 Lei K, Zhu DH: Jia zu xing xian liu xing xi rou bing de zhen zhi jin zhan. Xian Dai Yi Yao Wei Sheng 2015;2: 206-209.

64 An YF: Clinical study on familial adenomatous polyposis. Zhong Guo Xian Dai Yi Xue Za Zhi 2008;18:649-651.

65 Li H, Shi L, Wang WJ, et al: Clinical analysis familial adenomatous polyposis. Ning Xia Yi Xue Za Zhi 2011;2: 146-147.

66 Matsumoto T, Iida M, Kobori Y, et al: Serrated adenoma in familial adenomatous polyposis: relation to germline Apc gene mutation. Gut 2002,50:402-404.

$67 \mathrm{Xu} \mathrm{XD,} \mathrm{Fu} \mathrm{CG,} \mathrm{Song} \mathrm{N,} \mathrm{et} \mathrm{al:} \mathrm{Upper-gastrointestinal} \mathrm{polyps} \mathrm{found} \mathrm{in} \mathrm{cases} \mathrm{of} \mathrm{familial} \mathrm{adenomatous} \mathrm{polyposis.}$ Zhong Hua Pu Tong Wai Ke Za Zhi 2012;27:613-615.

68 Maehata Y, Eaaki M, Hirahashi M, et al: Duodenal adenomatosis in Japanese patients with familial adenomatous polyposis. Dig Endosc 2014;26(suppl 2):30-34.

69 Mantas D, Charalampoudis P, Nikiteas N, et al: FAP related periampullary adenocarcinoma. Int J Surg Case Rep 2013;4:684-686.

70 Liang XD, Wang GZ, Yang J: Jia zu xing xian liu xing xi rou bing ban ai bian 1 li fen xi. Zhong Guo Wu Zhen Xue Za Zhi 2008;8:6785-6786.

71 Nie Y, Zhang R, Fan K, et al: Familial adenomatous polyposis: a report of 10 cases in 3 generations of a family and literature review (in Chinese). Zhonghua Nei Ke Za Zhi 2014;53:290-292.

72 Lipton L, Tomlinson I: The multiple colorectal adenoma phenotype and MYH, a base excision repair gene. Clin Gastroenterol Hepatol 2004;2:633-638.

73 Cao HL, Wang BM, Cao XC: Clinical features of Gardner syndrome and Turcot syndrome in Chinese population: an analysis of 93 cases. Shijie Huaren Xiaohua Za Zhi 2010;36:3922-3925.

74 Ishikawa H: Chemoprevention of carcinogenesis in familial tumors. Int J Clin Oncol 2004;9:299-303.

$75 \mathrm{Li} \mathrm{J,} \mathrm{Lv} \mathrm{YM,} \mathrm{Gu} \mathrm{F,} \mathrm{et} \mathrm{al:} \mathrm{Long-term} \mathrm{effects} \mathrm{of} \mathrm{sulindac} \mathrm{on} \mathrm{familial} \mathrm{adenomatous} \mathrm{polyposis.} \mathrm{Zhong} \mathrm{Liu} \mathrm{Fang} \mathrm{Zhi}$ Yan Jiu 2008;35:888-891.

76 Wang J: Sai lai xi bu zhi liao he bing shang xiao hua dao xi rou de jia zu xing xian liu xing xi rou bing. Zhonghua Wai Ke Za Zhi 2005;43:196-197.

77 Li XL, He JT, Zhang YD, et al: Clinical study on familial adenomatous polyposis treated by high frequency electric cutting under endoscope combined with sulindac. Di Si Jun Yi Da Xue Xue Bao 2008;29:1494-1496.

78 Cao Y: Effects of celecoxib combined with high frequency electric cutting under endoscopy on familial adenomatous polyposis. Shi Yong Yao Wu Yu Lin Chuang 2011;3:209-211.

79 Zhang J, Cao H, Zhang B, et al: Berberine potently attenuates intestinal polyps growth in ApcMin mice and familial adenomatous polyposis patients through inhibition of Wnt signalling. J Cell Mol Med 2013;17:14841493.

-80 Wang LS, Burke CA, Hasson H, et al: A phase Ib study of the effects of black raspberries on rectal polyps in patients with familial adenomatous polyposis. Cancer Prev Res (Phila) 2014;7:666-674.

81 Liao GQ, Yan ZS: Surgical treatment of familial adenomatous polyposis. Zhong Guo Pu Tong Wai Ke Za Zhi 2004;13:276-278.

82 Yan ZS: Tui jian jia zu xing xian liu xing xi rou bing zhi liao zhi nan. Zhong Guo Pu Tong Wai Ke Za Zhi 2004; 13:319-320.

83 Wang SL, Gu GL: Present status and problems in diagnosis and treatment of Peutz-Jeghers syndrome. Shijie Huaren Xiaohua Za Zhi 2008;16:2385-2389.

84 Calva D, Howe JR: Hamartomatous polyposis syndromes. Surg Clin North Am 2008;88:779-817.

85 Chen HM, Fang JY: Genetics of the hamartomatous polyposis syndromes: a molecular review. Int J Colorectal Dis 2009;24:865-874.

86 Chow E, Macrae F: A review of juvenile polyposis syndrome. J Gastroenterol Hepatol 2005;20:1634-1640.

87 Li LJ, Wang ZQ, Wu BP: Peutz-Jeghers syndrome with small intestinal malignancy and cervical carcinoma. World J Gastroenterol 2008;14:7397-7399.

88 Sheng JQ, Cui WJ, Fu L, et al: APC gene mutations in Chinese familial adenomatous polyposis patients. World J Gastroenterol 2010;16:1522-1526. 
89 Hutchison J, Cohen Z, Onyeagucha BC, et al: How microRNAs influence both hereditary and inflammatorymediated colon cancers. Cancer Genet 2013;206:309-316.

90 Valeri N, Gasparini P, Fabbri M, et al: Modulation of mismatch repair and genomic stability by miR-155. Proc Natl Acad Sci USA 2010;107:6982-6987.

-91 Vasen HF, Watson P, Mecklin JP, et al: New clinical criteria for hereditary nonpolyposis colorectal cancer (HNPCC, Lynch syndrome) proposed by the International Collaborative group on HNPCC. Gastroenterology 1999;116:1453-1456.

92 Lynch HT, Smyrk T, McGinn T, et al: Attenuated familial adenomatous polyposis (AFAP). A phenotypically and genotypically distinctive variant of FAP. Cancer 1995;76:2427-2433.

93 Lipton L, Halford SE, Johnson V, et al: Carcinogenesis in MYH-associated polyposis follows a distinct genetic pathway. Cancer Res 2003;63:7595-7599.

94 Liu J, Li Q, Chen LR, et al: The diagnosis and management of familial juvenile polyposis. Zhong Hua Pu Tong Wai Ke Za Zhi 2006;21:553-556.

95 Yao L, Song JW: Chang xi rou fa sheng de xi bao he fen zi sheng wu xue yan jiu jin zhan. Shijie Huaren Xiaohua Za Zhi 2006;14:2958-2961.

-96 Hemminki A, Markie D, Tomlinson I, et al: A serine/threonine kinase gene defective in Peutz-Jeghers syndrome. Nature 1998;391:184-187.

97 Wang LJ, Ning JW, et al: Cheng ren wei you nian xing xi rou he you nian xing xi rou bing lin chuang bing li te zheng ji ai bian qu shi tan tao. Zhong Hua Xiao Hua Za Zhi 2005;25:43-44.

98 Wang SL, Mao GP, Gu GL: Peutz-Jeghers zong he zheng wei chang dao xi rou de 36 li zhen zhi jing yan. Zhong Hua Wei Chang Wai Ke Za Zhi 2009;12:428. 